\author{
Jurnal Kumara Cendekia \\ https://jurnal.uns.ac.id/kumara
}

\title{
UPAYA MENINGKATKAN KEMAMPUAN MENGURUTKAN POLA BENTUK 3 DIMENSI GEOMETRI DENGAN MEDIA PAPAN FLANEL
}

\author{
(Penelitian Tindakan Kelas pada Anak Kelompok A1 TK Cemara Dua \\ Surakarta Tahun Ajaran 2016/2017) \\ Restu Syamsi Nur Hikmah ${ }^{1}$, Peduk Rintayati ${ }^{2}$, Lies Lestari ${ }^{2}$ \\ 1 Program Studi PG PAUD Universitas Sebelas Maret \\ 2 Program Studi PGSD Universitas Sebelas Maret
}

Email : restu.syamsi@gmail.com, pedukrintayati@ymail.com , lies.pgsd@yahoo.co.id

\begin{abstract}
ABSTRAK
Penelitian Tindakan Kelas ini bertujuan meningkatkan kemampuan mengurutkan pola bentuk 3 dimensi geometri menggunakan media papan flanel pada anak kelompok A1 TK Cemara Dua Surakarta tahun ajaran 2016/2017. Penelitian ini dilaksanakan selama dua siklus. Setiap siklus terdiri dari perencanaan, pelaksanaan, observasi, dan refleksi. Subjek penelitian adalah anak kelompok A1 TK Cemara Dua Surakarta tahun ajaran 2016/2017 yang berjumlah 11 anak ( 6 laki-laki dan 5 perempuan). Teknik pengumpulan data melalui observasi, wawancara, tes unjuk kerja dan dokumentasi. Validitas data kuantitatif menggunakan validitas konstruk. Validitas data kualitatif menggunakan triangulasi sumber dan triangulasi teknik. Analisis data menggunakan teknik statistik deskriptif komparatif dan analisis interaktif. Hasil penelitian menunjukkan bahwa adanya peningkatan kemampuan mengurutkan pola bentuk 3 dimensi geometri dengan menggunakan media papan flanel dari pratindakan ke siklus I dan dari siklus I ke siklus II. Ketuntasan pada pratindakan sebesar $18,18 \%$, siklus I 45,45\%, dan siklus II 81,82\%. Peningkatan tersebut dibuktikan dengan meningkatnya kemampuan mengurutkan pola bentuk 3 dimensi geometri anak dalam mengurutkan 3 pola secara berurutan berdasarkan pada bentuk dan warnanya, dan anak mampu memperkirakan urutan selanjutnya dengan melengkapi urutan pola yang hilang berdasarkan bentuk dan warnanya.
\end{abstract}

Kata kunci: kemampuan mengurutkan pola, media papan flanel

\section{ABSTRACT}

The aim of this classroom action research is to improve the ability to sort 3 dimentional geometry shapes using flannel board media for children in group Al of Cemara Dua Surakarta Kindergarten in period 2016/2017. This research performed in two cycles. Each cycle consist of planning, implementation, observation, and reflection. The subject is group A children of Cemara Dua Surakarta Kindergarten in academic 2016/2017 which consist of 11 children ( 6 boys and 5 girls). Technique of collecting data through observation, interview, performance test and documentation. Validation of quantitative using construct validity. Validation of qualitative data using source triangulation and technique triangulation. Data analysis used comparative descriptive statistical and interactive analysis. The result shows that there is an 
improvement of the ability to sort 3 dimentional geometry shapes skill by using flannel board media of objects forming activity from precycle to cycle I and from cycle I to cycle II. The percentage pf throughness in precycle $18,18 \%$, in the first cycle increased to $45,45 \%$, and in the second cycle increased to $81,82 \%$. The increase is evidence by improved the children ability to sort 3 dimensional geometry shapes acording to shape and colour, and the child ability to estimate the next pattern by completing the missing pattern according to shape and colour.

Keywords: the ability to sort pattern, flannel board media 


\section{PENDAHULUAN}

Masa anak usia dini merupakan masa yang paling tepat untuk mengoptimalkan semua aspek perkembangan yang dimiliki anak. Salah satu aspek perkembangan yang perlu dikembangkan untuk anak usia dini adalah perkembangan kognitif, yaitu kemampuan untuk memecahkan masalah atau kemampuan menghubungkan, menilai dan mempertimbangkan sesuatu. Aspek kognitif pada anak usia dini dapat dikembangkan melalui pembelajaran mengurutkan pola.

Menurut Smith \& Price (2012), pola merupakan suatu urutan susunan yang sistematis berdasarkan bendabenda, simbol-simbol, bilangan-bilangan, bentuk-bentuk yang saling berhubungan. Hubungan yang terjadi dapat berdasarkan atas ukuran, warna, dan bentuk. Berdasarkan indikator dalam Permendikbud No 137 Tahun 2014 tentang Standar Nasional Pendidikan Anak Usia Dini, anak kelompok A harus mampu mengenal pola (misal, $\mathrm{AB}-\mathrm{AB}$ dan $\mathrm{ABC}-\mathrm{ABC}$ ) dan mengulanginya. Kemampuan untuk mengurutkan pola sangat penting karena mengurutkan pola dapat membantu anak untuk mengembangkan keterampilan berfikir logis anak usia dini. Warren dan Cooper
(2006) menerangkan bahwa mengurutkan pola dapat membantu anak-anak untuk memulai mengeksplorasi konsep hubungan dalam kemampuan berpikirnya. Konsep hubungan seperti urutan ukuran, bentuk, angka, warna yang ada dalam kehidupan. Sedangkan anak yang mengalami kesulitan dalam mengurutkan pola akan mengalami kesulitan dalam memahami bahasa matematika yang berhubungan dengan penyusunan dan pengamatan dalam kehidupannya.

Pada anak usia 3-5 tahun, anak sudah mulai berpikir tentang simbol dan lambang, sehingga untuk mengembangkan kemampuan berpikir logis dalam mengurutkan pola perlu kiranya dikenalkan dengan simbol ataupun lambang yang mudah diterima anak. Simbol yang mudah dikenalkan pada anak usia dini yaitu berupa bentuk 3 dimensi geometri yang mudah dijumpai anak dalam kehidupan sehari-hari seperti kubus, tabung dan bola. Negoro (2014) menjelaskan bahwa bentuk 3 dimensi geometri merupakan bangun ruang yang memiliki panjang, tinggi dan lebar. Bentuk 3 dimensi geometri juga dapat dilihat dari berbagai arah, kanan-kiri, atas- bawah, depan-belakang. Oleh 
karena itu peneliti memilih bentuk 3 dimensi geometri kubus, tabung dan bola dalam pembelajaran mengurutkan pola untuk menciptakan pembelajaran yang nyata yaitu dengan menghubungkannya dengan benda-benda dalam kehidupan sehari- hari, misalnya kubus seperti dadu, bola seperti bakso, tabung seperti kaleng susu.

Berdasarkan kegiatan prasiklus yang telah dilakukan pada tanggal 11 januari 2017 pada anak kelompok A1 TK Cemara Dua Surakarta dapat diketahui bahwa kemampuan anak dalam mengurutkan pola bentuk 3 dimensi geometri masih belum maksimal. Dari data yang diperoleh dalam kegiatan prasiklus menunjukkan bahwa dari 11 anak, hanya 2 anak atau 18,18\% yang dikatakan dalam kategori tuntas dan 9 anak atau $81,82 \%$ dikatakan belum mencapai ketuntasan. Belum maksimalnya kemampuan anak dalam kegiatan mengurutkan pola ini dapat dilihat dari anak yang masih bingung dan mengurutkan pola hanya berdasarkan warnanya saja atau bentuknya saja. Anak kurang aktif dan kurang antusias ketika mengikuti pembelajaran mengurutkan pola. Hal ini disebabkan oleh beberapa faktor, yaitu faktor internal dan faktor eksternal. Dalyono (2015) menyebutkan bahwa yang termasuk faktor internal anak meliputi kesehatan, minat, dan motivasi, sedangkan faktor eksternal meliputi faktor keluarga, sekolah, dan masyarakat.

Penggunaan variasi media pembelajaran yang mendukung pembelajaran, diperlukan untuk mengatasi kejenuhan anak dalam belajar dan menstimulasi anak untuk berekploarisi dalam menggali pengetahuan yang baru. Salah satu media yang dapat digunakan untuk meningkatkan kemampuan mengurutkan pola bentuk 3 dimensi geometri adalah dengan menggunakan media papan flanel. Daryanto (2013) mengemukakan bahwa media papan flanel merupakan suatu papan yang dilapisi kain flanel atau kain yang berbulu dimana padanya diletakkan potongan gambar-gambar atau simbol-simbol lain. Media papan flanel memiliki warna yang beraneka ragam sehingga dapat menarik perhatian dan minat anak-anak.

Selain itu, media papan flanel dapat dipakai berkali-kali, bentuk-bentuk 3 dimensi geometri mudah ditempelkan dan dilepaskan, serta penyajiannya dapat membuat lebih efisien.

\section{Konsep Pola untuk Anak Usia Dini} Smith dan Price (2012) menyatakan, "pattern can be as systematic arrangement of numbers or shapes which follows a given rule". 
Pernyataan tersebut menjelaskan bahwa pola merupakan suatu urutan susunan yang sistematis berdasarkan bendabenda, simbol-simbol, bilangan-bilangan, bentuk-bentuk yang saling berhubungan. Penelitian ini menggunakan bentuk 3 dimensi geometri berupa bentuk kubus, tabung dan bola dengan menggunakan warna merah, kuning dan hijau.

Seefeldt dan Wasik (2008) mengungkapkan bahwa kegiatan mengurutkan pola dapat membantu anakanak mengembangkan pengetahuan tentang urutan pengetahuan dan hubungan. Selain itu, kemampuan untuk mengenal pola akan membantu anakanak mengembangkan keterampilan yang dipakai dalam menyortir, menggolongkan, mengidentifikasi bentuk-bentuk dan membuat grafik. Untuk memahami pola, anak harus mampu untuk mengidentifikasi warna, bentuk, ukuran, tekstur, posisi dan kuantitas. Copley dalam Beaty (2013) menjelaskan "banyak penelitian telah membuktikan, fokus pada konsep pola sangat efektif dalam memfasilitasi kemampuan anak-anak membuat generalisasi tentang kombinasi angka, strategi menghitung, dan penyelesaian soal".

Karakteristik perkembangan berpikir logis anak usia 4-5 tahun atau kelompok A menurut Permendikbud No 137 tahun 2014 antara lain; mengklasifikasikan benda berdasarkan fungsi, bentuk, atau warna atau ukuran; (2) mengenal gejala sebab-akibat yang terkait dengan dirinya; mengklasifikasikan benda ke dalam kelompok yang sama atau kelompok yang sejenis atau kelompok yang berpasangan dengan 2 variasi; (4) mengenal pola (misal, AB-AB dan ABC$\mathrm{ABC}$ ) dan mengulanginya dan; (5) mengurutkan benda berdasarkan 5 seriasi ukuran atau warna.

\section{MEDIA PAPAN FLANEL}

Menurut Indriana (2011) media papan flanel adalah papan yang berlapis kain flanel untuk menyajikan gambargambar atau kata-kata yang mudah ditempel dan mudah pula dilepas. Media papan flanel dapat dibuat sendiri oleh guru dengan menggunakan papan dan dilapisi oleh kain flanel dengan warna yang cerah sehingga mampu menarik perhatian dan minat anak. Sanaky (2011) menyebutkan beberapa kelebihan media papan flanel, yaitu gambar- gambar dengan mudah ditempelkan, efisiensi waktu dan tenaga, menarik perhatian anak dan memudahkan guru menjelaskan materi pembelajaran. Penggunaan media papan flanel harus memperhatikan 
beberapa kekurangannya, sehingga guru dapat meminimalisir kekurangan media papan flanel pada saat digunakan dalam menyampaikan materi pembelajaran. Sukiman (2012) menyebutkan beberapa kekurangan media papan flanel antara lain, memerlukan waktu yang lama untuk menyiapkan materi, memerlukan biaya yang mahal untuk mempersiapkannya, sukar menampilkan pada jarak yang jauh, dan kain flanel mempunyai daya rekat yang kurang kuat. Prinsip penggunaan media papan flanel antara lain; (1) mempersiapkan papan yang berfungsi untuk menempelkan bentuk-bentuk, dengan diberi perekat berupa kain perekat (velcro); (2) mempersiapkan kain flanel untuk membungkus papan; (3) mempersiapkan bentuk-bentuk yang akan ditempel pada papan flanel tersebut dan diberi kain perekat (velcro) agar mampu menempel dengan kuat; (4) media papan flanel siap digunakan.

\section{METODE}

Pendekatan yang digunakan adalah pendekatan kuantitatif dan kualitatif. Penelitian ini merupakan Penelitian Tindakan Kelas yang dilakukan selama dua siklus, setiap siklus terdiri dari 4 tahap, yaitu: perencanaan, tindakan, observasi, dan refleksi. Subjek penelittian ini adalah anak kelompok A1 TK Cemara Dua Surakarta tahun ajaran 2016/2017 dengan jumlah murid 11 anak, yang terdiri dari 6 anak laki-laki dan 5 anak perempuan. Sumber data dalam penelitian meliputi sumber data primer dan sumber data sekunder. Teknik pengumpulan data yang dilakukan oleh peneliti menggunakan observasi, wawancara, dokumentasi, dan tes unjuk kerja. Validitas data kuantitatif menggunakan validitas konstruk dan validitas data kualitatif menggunakan triangulasi teknik dan triangulasi sumber. Analisis data menggunakan teknik analisis deskriptif komparatif untuk membandingkan hasil antar siklus dan menggunakan model analisis interaktif yang meliputi pengumpulan data, reduksi data, penyajian data dan penarikan kesimpulan.

\section{HASIL DAN PEMBAHASAN}

Berdasarkan hasil observasi yang dilakukan sebelum tindakan menunjukkan bahwa kemampuan mengurutkan pola anak kelompok A1 masih tergolong rendah, masih ada beberapa anak yang belum mencapai nilai ketuntasan. Hal ini dibuktikan dari presentase nilai rata-rata kemampuan mengurutkan pola anak kelompok A1 yang berjumlah 11 anak, hanya terdapat 2 anak $(18,18 \%)$ yang memiliki kemampuan mengurutkan pola dengan baik, 9 anak (81,82\%) yang memiliki kemampuan mengurutkan pola masih 
kurang. Data tersebut menunjukkan bahwa sebagian besar anak belum memiliki kemampuan mengurutkan pola yang baik dan diperlukan peningkatan.

Peneliti melakukan tindakan untuk memperbaiki kemampuan mengurutkan pola pada anak kelompok A1 TK Cemara Dua Surakarta yang masih kurang yaitu dengan penggunaan media papan flanel. Berdasarkan hasil penelitian menunjukkan bahwa presentase nilai indikator pencapaian $75 \%$ dengan 5 anak $(45,45 \%)$ memiliki kemampuan mengurutkan pola dengan baik, dan 6 anak (54,55\%) memiliki kemampuan mengurutkan pola yang kurang. Karena pada siklus I belum mencapai indikator kinerja yang ditentukan yakni $75 \%$ anak yang memiliki kemampuan mengurutkan pola dengan benar, maka dilakukan tindakan siklus ke II yang dilakukan sesuai refleksi siklus I agar kekurangan pada siklus I dapat ditingkatkan pada siklus

II. Hasil penelitian pada siklus II, menunjukkan bahwa presentase nilai indikator pencapaian sebesar $75 \%$ dengan 9 anak $(81,82 \%)$ telah memiliki kemampuan mengurutkan pola bentuk 3 dimensi geometri yang baik dan sisanya 2 anak $(18,18 \%)$ masih memiliki kemampuan mengurutkan pola bentuk 3 dimensi geometri yang kurang. Data tersebut menunjukkan bahwa kemampuan mengurutkan pola bentuk 3 dimensi geometri anak meningkat dengan baik dan telah memenuhi target pencapaian indikator dengan presentase sebesar $75 \%$ sehingga tidak dilakukan tindakan pada siklus selanjutnya.

Setelah dianalisis pada siklus I dan siklus II, maka kemampuan mengurutkan pola bentuk 3 dimensi geometri pada anak kelompok A1 TK Cemara Dua Surakarta mengalami peningkatan sesuai indikator penilaian. Hasil penilaian kemampuan mengurutkan pola bentuk 3 dimensi geometri secara rinci dapat dilihat pada Gambar 1. 


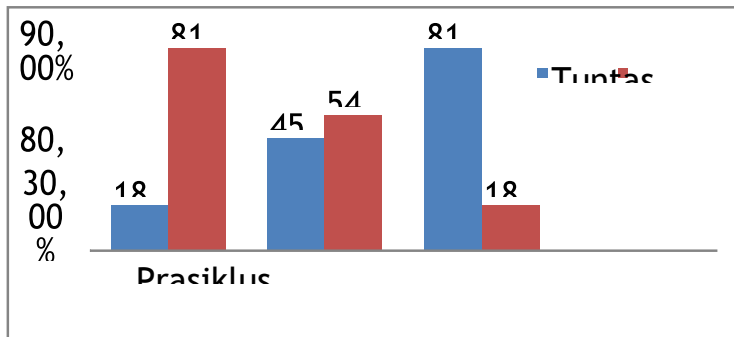

Gambar 1. Perbandingan Nilai Kemampuan Mengenal Konsep Bilangan Pada Prasiklus, Siklus I dan Siklus II

\section{Peningkatan kemampuan} mengurutkan pola bentuk 3 dimensi geometri tersebut sesuai dengan karakteristik anak usia 4-5 tahun menurut Permendikbud No 137 tahun 2014 yaitu mengenal pola (misal, $A B-A B$ dan $A B C-A B C)$ dan mengulanginya. Peningkatan tersebut dibuktikan dengan semakin meningkatnya masing-masing indikator. Peningkatan terlihat ketika anak mampu mengurutkan 3 pola secara berurutan berdasarkan pada bentuk dan warnanya, dan anak mampu memperkirakan urutan selanjutnya dengan melengkapi urutan pola yang hilang berdasarkan bentuk dan warnanya. Hal ini sejalan dengan pendapat Asmawati (2014) yang mengemukakan bahwa anak usia 4-5 tahun diharapkan mampu meniru pola dengan menggunakan berbagai bentuk dan memperkirakan urutan berikutnya setelah melihat bentuk 2-3 pola yang berurutan.

Peningkatan kemampuan mengurutkan pola bentuk 3 dimensi geometri anak melalui penggunaan media papan flanel sesuai dengan penelitian yang telah dilakukan oleh Hudaya dan Sri Widayati (2015) dengan judul Peningkatan Kemampuan Literasi Melalui Media Pembelajaran Menggunakan Media Papan Flanel di Kelompok B TK Kartika IV-53 bahwa pembelajaran dengan penggunaan media papan flanel dapat meningkatkan kecerdasan kognitif anak usia dini. Mengurutkan pola membantu anak-anak untuk memahami suatu urutan dan hubungan tertentu, membantu anak-anak memprediksi sesuatu yang akan muncul apabila sebelumnya terjadi sebuah peristiwa tertentu. Hal ini sejalan dengan Beaty (2013) yang mengemukakan bahwa Mempelajari pola membantu anak-anak prasekolah memprediksi apa yang akan terjadi selanjutnya, terutama dalam sebuah cerita. Kemampuan anak dalam mengurutkan pola harus dimiliki sebelum anak memahami dan mempelajari pengetahuan matematika yang lebih luas di tahap pendidikan dasar. Allison Bock, Cartwright, Christian Gonzalez. Sarah Obrien, Melissa F. Robinson, Katrina Schmerold, Amber Shriver, dan Robert Pasnak (2015) dalam penelitian yang berjudul "The Role of Cognitive Flexibility in Pattern Understanding" mengemukakan pendapat yang sejalan, bahwa kegiatan mengurutkan pola adalah kemampuan pertama yang harus dimiliki anak sebelum anak memahami kemampuan matematika pra-aljabar. Hasil ketuntasan membuktikan bahwa dengan menggunakan media papan flanel dapat meningkatkan kemampuan mengurutkan pola bentuk 3 dimensi geometri pada anak karena dalam pelaksanaannya, media papan flanel membuat anak menjadi lebih tertarik mengikuti pembelajaran karena warna papan flanel yang cerah dan bentuk-bentuk 3 dimensi geometri yang unik.

Penggunaan media papan flanel membuat anak memperoleh pengetahuan baru yang belum pernah dijumpai sebelumnya serta membuat anak lebih mudah untuk memahami materi pembelajaran 


\section{PENUTUP}

Hasil penelitian tindakan kelas yang dilaksanakan dalam 2 siklus dengan penggunaan media papan flanel dapat disimpulkan bahwa melalui penggunaan media papan flanel dapat meningkatkan kemampuan mengurutkan pola bentuk 3 dimensi geometri pada anak kelompok A1 TK cemara Dua Surakarta Tahun Ajaran 2016/2017. Hal ini dibuktikan dengan adanya peningkatan persentase kemampuan mengurutkan pola bentuk 3 dimensi geometri anak pada tiap siklus, yaitu dalam kegiatan prasiklus, hanya terdapat sebanyak 2 anak atau 18,18\% dari 11 anak yang dikatakan tuntas. Pada hasil penelitian siklus I menunjukkan sebanyak 5 anak atau 45,45\% dari 11 anak yang dikatakan tuntas, dan pada siklus II terdapat 9 anak atau 81,82\% dari 11 anak yang dikatakan tuntas.

Hasil ketuntasan pada siklus II telah mencapai target yang diharapkan, sehingga menjadi bukti bahwa kegiatan mengurutkan pola bentuk 3 dimensi geometri menggunakan media papan flanel dapat menjadi salah satu alternatif yang dapat diberikan kepada anak dalam mengatasi permasalahan belajar anak khususnya dalam meningkatkan kemampuan berpikir logis anak. Melalui pembelajaran mengurutkan pola menggunakan media papan flanel, kegiatan pembelajaran menjadi lebih menyenangkan dan dapat menarik minat dan perhatian anak.

Beberapa implikasi berdasarkan hasil penelitian yang telah dilakukan, diantaranya sebagai berikut : (1) Bagi anak, hasil penelitian menunjukkan bahwa penggunaan media papan flanel dapat meningkatkan kemampuan anak dalam mengurutkan pola, sehingga media papan flanel dapat dijadikan sebagai alternatif dalam proses pembelajaran; (2) Bagi guru, hasil penelitian memberikan kesempatan kepada guru untuk mengembangkan kemampuan mengajar dengan menggunakan media papan flanel dan melakukan inovasi dalam setiap pembelajaran; (3) Bagi sekolah, hasil penelitian memberikan masukan kepada sekolah untuk meningkatkan mutu belajar kreatif dan inovatif, serta dapat memberikan sumbangan yang positif dengan menerapkan media papan flanel dalam kegiatan pembelajaran yang berkaitan. 
DAFTAR PUSTAKA

Asmawati, L. (2014). Perencanaan Pembelajaran PAUD. Bandung: PT Remaja Rosdakary Beaty, J. J. (2013). Observasi Perkembangan Anak Usia Dini. (A. Rakhman, Penerj.) Jakarta: Kencana. Bock, A., Cartwright, Gonzalez, C., Obrien, S., Robinson, M., \& Schmerold, K. (2015). The Role Of Cognitive Flexibility in Pattern Understanding Journal of Education and Human Development. Journal of Education and Human Development, 4(1), 1925.

Dalyono. (2015). Psikologi Pendidikan. Jakarta: Rineka Cipta.

Daryanto. (2013). Media Pembelajaran. Yogyakarta: Penerbit Gava Media.

Departemen Pendidikan Nasional. (2014). Peraturan Menteri Pendidikan dan Kebudayaan Republik Indonesia Nomor 137 Tahun 2014 tentang Standar Pendidikan Anak Usia Dini. Jakarta: Departemen Pendidikan Nasional.

Hudaya, L., \& Widayati, S. (2015). Peningkatan Kemampuan Literasi Melalui Pembelajaran Menggunakan
Media Papan Flanel di Kelompok B. Paud Teratai, 4(2). Dipetik Desember 29, 2016, dari http://ejournal.unesa.ac.id

Indriana, D. (2011). Ragam Alat Bantu Media Pengajaran. Yogyakarta: Diva Press.

Negoro, S. \&. (2014). Ensiklopedia Matematika. Bogor: Penerbit Ghalia Indonesia.

Sanaky, H. (2011). Media Pembelajaran.

Yogyakarta: Penerbit Kaukaba.

Seefeldt, C. \& Wasik. (2008). Menyiapkan Anak Usia Tiga, Empat, dan Lima tahun Masuk Sekolah.

(P. Nasar, Penerj.) Jakarta: PT Indeks.

Smith, A. \& Price. (2012). Mathematics in Early Years Education (Third Edition ed.). New York: Routledge.

Sukiman. (2012). Pengembangan Media Pembelajaran. Yogyakarta: Pustaka Insan Madani.

Warren, E., Cooper, T. (2006). Using Repeating Pattern To Explore Functional Thinking. Australian Primary Mathematics Classrom, 11, 9-14. Diperoleh tanggal 26 Januari 2017, diakses melalui http://eric.ed.gov. 
KUMARA CENDEKIA Vol. 7 No.3 September 2019 